\title{
An aggregate travel cost approach to valuing forest recreation at managed sites
}

\author{
Peter C. Boxall ${ }^{1}$, Bonita L. McFarlane ${ }^{1}$ and Michael Gartrell ${ }^{1}$
}

Travel cost models were estimated for camping trips to designated recreation areas in the Rocky-Clearwater Forest in Alberta during 1994. Trips were aggregated by postal code and resulting trip counts from each postal code were utilized in truncated Poisson and negative binomial regressions. The study involved the design of a camping fee collection permit which allowed a census of users rather than a sample to be utilized in the analysis. Per trip consumer surplus estimates resulting from the Poisson model revealed that aggregate nonmarket benefits provided by the Alberta Land and Forest Service forest recreation areas were about $\$ 750,000$ in 1994. The study suggests that with little effort and some planning, fee collection permit systems can be used in concert with travel cost and geographic information systems to provide estimates of some nontimber values in Canada's forests.

Key words: nontimber values, camping, travel cost models, forest recreation, geographical information systems
Des modèles de frais de déplacement ont été élaborés pour des excursions de camping effectuées dans des zones désignées de la Forêt Rocky-Clearwater en Alberta au cours de 1994. Les excursions ont été regroupées selon les codes postaux et le dénombrement des excursions par code postal a été utilisé dans des régressions tronquées de Poisson et binominales négatives. L'étude comportait la conception d'un système de collecte des frais de permis de camping qui permettrait un recensement des campeurs plutôt qu'un échantillon destiné à être utilisé lors de l'analyse. Les estimés de surplus par utilisateur découlant du modèle de Poisson soulignaient que les bénéfices non-commerciaux regroupés tels qu'identifiés par les Territoires récréatifs du Service des Terres et Forêts de l'Alberta atteignaient près de 750000 \$ en 1994. L'étude laisse entendre qu'avec un peu d'effort et de planification, les systèmes de collecte des frais de permis pourraient être utilisés en conjonction avec les frais de déplacement et les systèmes d'information géographique pour élaborer des estimés de certaines des valeurs autres que ligneuses en provenance des forêts canadiennes.

Mots clés: valeurs autres que ligneuses, camping, modèles de frais de déplacement, activités récréatives forestières, systèmes d'information géographique

\section{Introduction}

Nontimber values continue to be a major concern in the management and allocation of Canada's forests. Many of these values are difficult to measure and incorporate explicitly in management initiatives. A major reason for this difficulty is a lack of market prices associated with many non-fibre uses of forests. This is particularly true of Canada's forests, the vast majority of which are publicly owned and which provide opportunities to many forms of forest recreation.

In this paper the economic value of one specific recreational forest use in Alberta's foothills, camping at sites designated as forest recreation areas by the Alberta Land and Forest Service is assessed. These sites provide basic amenities to campers at a price which has not been determined in an economic market. Thus, it is hypothesized that these areas provide nonmarket benefits to users over the fees collected. Understanding the magnitude and distribution of nonmarket recreation benefits is important because there are considerable pressures for the development of tourism and recreation enterprises in the province which may compete with traditional types of forest recreation.

While knowledge of the economic benefits of recreation in managing public lands is important for examining land allocation, such knowledge can be expensive to acquire.

\footnotetext{
${ }^{1}$ Northern Forestry Centre, Canadian Forest Service, 5320122 Street, Edmonton Alberta, Canada T6H 3S5.
}

Thus, investigating existing data collection systems and devising methods to improve these systems are meaningful. This paper will demonstrate ways to improve existing data collection processes and utilize the resulting data in economic models that provide estimates of recreation benefits. The processes can also provide a better understanding of recreation demand that can inform development plans and minimize impacts on traditional forest recreation use.

\section{Forest Recreation in the Rocky-Clearwater Forest}

The Rocky-Clearwater Forest is a 1.8 million ha area that comprised one administrative land unit in the Alberta Department of Environmental Protection during 1994 (Fig. 1). There is one provincial park in this forest and 33 forest recreation areas (FRAs) that collect camping fees. The FRAs have been managed by the Alberta Forest Service for about 35 years. The FRAs provide semi-primitive camp sites and are usually located close to recreational or scenic amenities such as streams, lakes, or waterfalls. The FRAs range in size from 6 to 91 campsites.

User statistics, including estimates of total use, are compiled annually by Alberta Land and Forest Service staff based on periodic inspections of the campgrounds. On-site surveys have also been conducted at selected FRAs since 1983. Although this information was important for internal planning purposes, it lacked information necessary for travel cost 


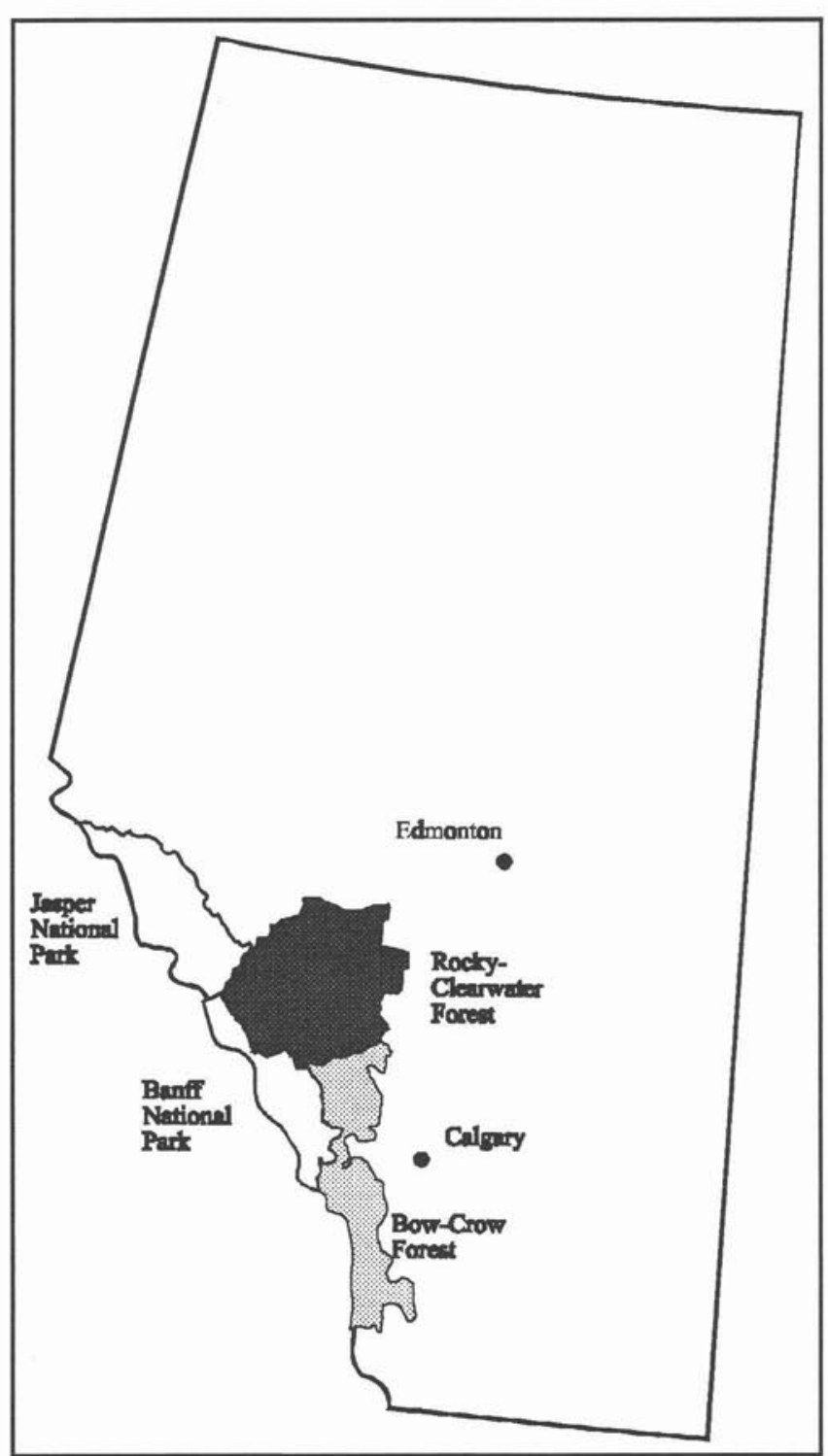

Fig. 1. The Rocky-Clearwater and Bow-Crow Forests in Alberta.

analyses. Furthermore, inconsistencies in estimating total use resulted in the user statistics not indicating actual use. For these reasons a census of users was possibly a more appropriate procedure.

Since 1992 camping fees have ranged from $\$ 5.50$ to $\$ 9.00$ night $^{-1}$. The system of collecting this fee involves a registration envelope or permit which requires a camper to provide information needed to verify payment such as their site number, vehicle licence plate number, date, nights paid, last name, and enclosed amount. During 1993 we designed a sticker that was added to the envelope. It asked registrants to provide the number of individuals in their camping party, the number of past visits to the campground during the past 10 years, and their home postal code. This additional information was used to determine the campers' origin and their frequency of use of FRAs. Postal codes linked the permits to residence locations and Statistics Canada census data. Travel cost models, which were used to estimate the economic benefits associated with the provision of FRAs, were constructed from this.
From May to October 1994 a detailed examination of recreation at FRAs in the Rocky-Clearwater Forest was conducted (McFarlane et al. 1996). This involved three phases: 1) the collection of permits with the expanded information provided by the stickers, 2 ) an on-site interview of campers at selected FRAs, and 3) a mail survey of the sample of campers interviewed on site. In this paper the permit database is linked with Statistics Canada census and road network data using geographic information systems (GIS) technology. Economic models were constructed that provide estimates of the economic value of camping, and provide some insights into the general characteristics of the FRA users. The specific objectives of this analysis were to show how recreation permits can be improved to collect data required for developing economic valuation models and to demonstrate how existing data and technology can be used in this process.

\section{Travel Cost Models}

Travel cost models utilize the assumption that the costs of travelling between an individual's residence and a recreation site are a proxy for the price of recreation. In this regard the model relies on actual behaviour in that the site choices of individuals must be observed by the investigator, and that market purchases associated with this behaviour (travel costs) are weakly complementary to the choice of a recreation site (Fletcher et al. 1990). If there is sufficient variation in the distances between visitors' residences and the recreation sites, and in the numbers of trips taken during a particular time period, then a statistical model can be estimated that explains the numbers of trips taken as a function of the travel costs. This model is called a demand curve in economic theory, and the area under this curve but above the actual amounts spent visiting the site, provide an estimate of the value of the site. This area is called consumer surplus. It essentially describes the amounts individuals are willing to pay over what they actually pay for a nonmarket good, and provides the basis of the estimation of nonmarket values (McKenney and Sarker 1994).

There are many different types of travel cost models (Fletcher et al. 1990). They require different types of data, can be used for different objectives, and require a variety of behavioural and statistical assumptions. The traditional TCM was chosen as the appropriate model because the goal was to estimate recreation values and not recreation quality changes. A limited amount of information was also available from the permit data. Furthermore, while some information was available on individual visits to FRAs (e.g. from vehicle licence plates), it was incomplete and was difficult to associate with similar individual level socioeconomic data. On the other hand, the postal code information was completed on permits and it was possible to link postal codes with socioeconomic data from the national census (see below). For these reasons an aggregate or zonal TCM was chosen as the appropriate model.

A recent precedent in the choice of this type of TCM is a study by Hellerstein (1991) who used aggregated data in estimating the value of recreation in the Boundary Waters Canoe Area in northern Minnesota. He faced a similar problem in using permit data that did not contain information on the number of prior trips by individual visitors. Hellerstein combined zip code level data into county level aggregates which allowed the inclusion of zero trip quantities from counties that did not visit the recreation area, and also introduced the use of count data 
models in aggregate travel cost analysis. These models explicitly recognize the count nature of trip demand in that recreation trips can occur only in nonnegative integer quantities. This is in contrast to other aggregate TCMs, which use ordinary least squares regression models that allow negative and noninteger trip quantities and with certain functional forms cannot include zero trip quantity decisions.

In our empirical application, the postal code was the unit of analysis, but only those postal codes from which trips occurred were included. Thus, the distribution of trip data is "truncated" at zero because only the postal codes from which at least one trip occurred are included in the analysis. This kind of data requires truncated count models, which are well known (Grogger and Carson 1988). Our study thus utilized truncated count estimators with aggregate data in examining the demand for recreation in this forest in Alberta. Furthermore, the study used a census of users rather than a sample.

\section{Methods}

\section{Permit Database}

From about 15 May to 15 October 1994, 18,985 permits were obtained from the 33 FRAs that collected fees. Of these, 18,350 contained complete information and were entered into a PARADOX computer database. Analysis of this data identified that $90 \%$ of registrants were from Alberta with the remainder from British Columbia (4.0\%), Saskatchewan $(1.9 \%)$, and Manitoba (0.5\%). Other origins included the United States $(2.1 \%)$ and Europe $(1.0 \%)$. Given the high probability of multiple destinations for most visitors not residing in Alberta, and the possibility of spatial limits on travel cost analysis (Smith and Kopp 1980) for trips to the RockyClearwater Forest, we reduced the permit data to include only those individuals who reside in Alberta. This final data set contained complete information on 13,997 trips to the forest lasting one or more nights.

This is an aggregate travel cost analysis, and the unit of analysis is the postal code. The trips came from 4,798 identifiable postal codes in Alberta. The majority of trips originated from small towns and rural areas located within a one to two hour drive from the forest. Only about $31 \%$ of trips originated from the two major urban centres of Edmonton and Calgary. McFarlane et al. (1996) provide a detailed analysis of the geographical distribution of these codes. There was an average of 2.68 trips per postal code to the FRAs. Over $65 \%$ of the postal codes contributed one trip, while the maximum number of trips from one single postal code was 537 .

\section{GIS Analysis}

In most TCM analyses, travel distances are measured by hand from a map along an assumed route using a ruler, planimeter, or similar device. These manual approaches are labour intensive, time consuming, and include a large error component. Utilising a technology known as Geographic Information Systems (GIS), one can increase precision while at the same time reducing costs by programming the measurement mechanism for a computer.

The first component of this automated procedure (Fig. 2) linked the postal code from each survey record to a 1991 enumeration area (EA) centroid using the postal code conversion file (PCCF) from Statistics Canada (Statistics Canada 1992). Of the 13,997 permits, 12,772 matched a postal code in the PCCF.

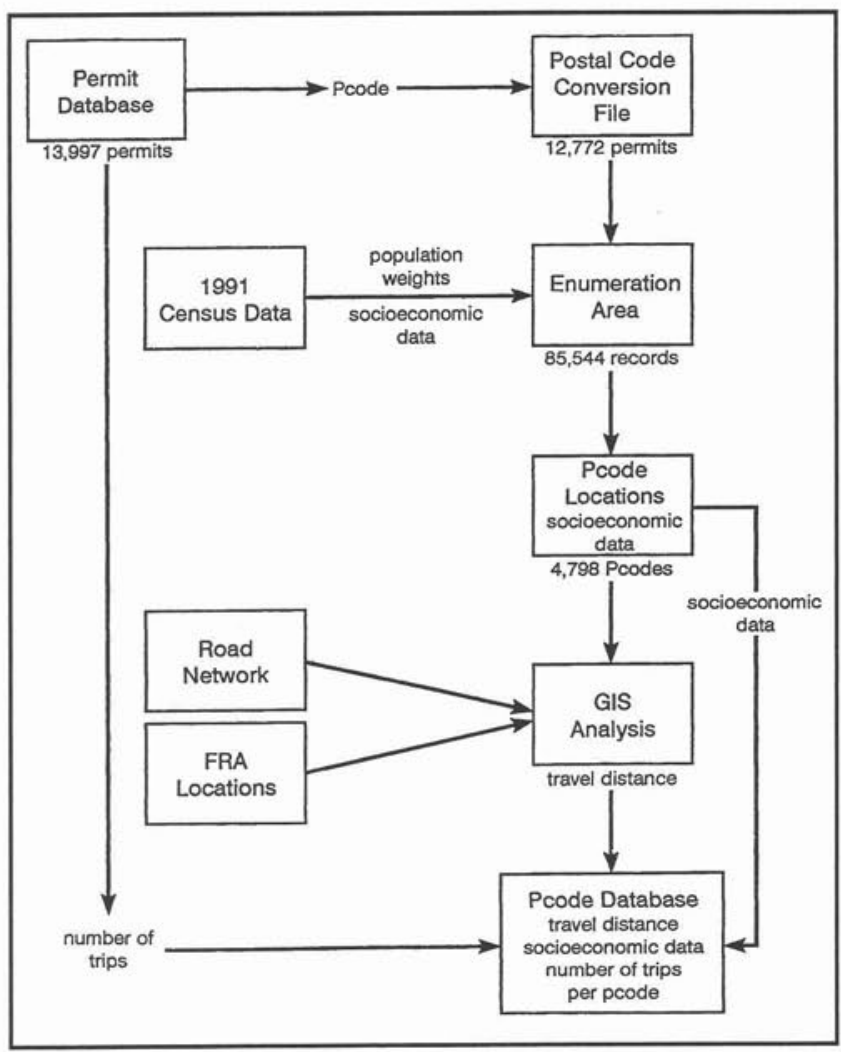

Fig. 2. A diagram showing the construction of the final aggregate postal code database used in the travel cost analysis.

Nonmatches involved missing or invalid postal codes. Linking these to EAs resulted in a database containing 85,544 records because postal codes can include or intersect more than one EA. These multiple linkages pose a challenge in that to measure a travel distance, a camper's origin must be resolved to a single geographic point. In order to represent each postal code as a single point, each postal code linked to more than one EA centroid was placed at the geometric mean of the EA centroids weighted by each EA's 1991 census population. This procedure allowed the estimation of a point which reflects the relative probability of a permit location based on population. Furthermore, since a postal code was linked to census data through the EA, socioeconomic characteristics of individuals from the postal codes could also be estimated. McFarlane et al. (1996) provide further details of this aspect of the study.

Since the purpose of this study was to estimate the value of FRA use in the Rocky-Clearwater Forest we used one FRA, Fish Lake, located close to the middle of the forest on the main highway as an approximate destination point for all FRA visits. The Fish Lake FRA area (including Goldeye Lake located about two $\mathrm{km}$ from Fish Lake) is the most popular destination in this forest (McFarlane et al. 1996). Ghost Lake FRA, another popular destination in the adjacent Bow-Crow Forest (Fig. 1), was used as a likely substitute site for RockyClearwater visitors. Ghost Lake and Fish Lake's locations were digitized and matched to the digitized Alberta highway network which was derived from ESRI Inc. (1992). With the postal code location, destination, and road network databases assembled, the GIS was used to compute the shortest distance along the roads between each pair of origin and destination points (Fig. 2). 
The sources of error in the estimation of origins and distance measurements, and their anticipated impact on subsequent travel costs, is a subject for future examination. However, we expect errors in measuring distances to be minimal, and feel confident that they are at least as good as distance measurements used in other aggregate travel cost studies for example Richards and Brown (1992) and Hellerstein (1991).

\section{Statistical Analysis}

Recreation data, such as the data gathered here, are typically characterized by its count nature, where recreation trips are nonnegative integers, and truncation, which means that information about people who do not visit the sites is not available. These features have been recognized through the development of truncated count regression estimators (Grogger and Carson 1988), and a number of applications in recent empirical work (Creel and Loomis 1990; Offenbach and Goodwin 1994). Untruncated count estimators were described by Hellerstein (1991) and Yen and Adamowicz (1993).

The initial statistical model uses a positive Poisson probability distribution for the dependent variable $Y_{\mathrm{i}}$ (the number of visits from a postal code):

$$
P\left(Y=y_{i} \mid y_{i}>0\right)=\frac{\exp \left(-\lambda_{i}\right) \lambda_{i}^{y_{i}}}{y_{i} !\left(1-\exp \left(-\lambda_{i}\right)\right)}
$$

where $y_{\mathrm{i}}=1,2, \ldots \ldots$. , and $i$, which indexes individuals, $=1,2, \ldots$. , $n$. Note in this case that the positive Poisson distribution involves truncation at 0 so that only values of 1 or more are permitted. A common specification chosen for $\lambda$, is $\lambda_{i}=$ $\exp \left(x_{i} \beta\right)$, where $x_{i}$ is a vector of exogenous variables and $\beta$ represents a vector of parameters to be estimated. The log-likelihood function, described by Grogger and Carson (1988), resulting from (1) allows estimation of parameters using maximum likelihood methods. An undesirable feature of Poisson count models, however, is the assumption that the conditional mean and variance are equal and in the truncated case the conditional variance is smaller than the mean (Yen and Adamowicz 1993). This is especially problematic in empirical research because conditional variances are typically greater than conditional means in socioeconomic data, leading to an effect called overdispersion. The presence of overdispersion allows consistently estimated means of parameter estimates (Gourieroux et al. 1984), but causes the standard errors of these estimates to be biased downward, resulting in erroneous tests of their statistical significance (Cameron and Trivedi 1986).

The equality of the mean and variance property of Poisson count models has resulted in the development of the negative binomial model (Hausman et al. 1984). This model allows for overdispersion by compounding the Poisson distribution with a gamma distribution. This allows heterogeneity to be gamma distributed. In the case of truncation at 0 , the distribution of $Y_{\mathrm{i}}$ is:

$$
\begin{aligned}
& P\left(Y_{i}=y_{i} \mid y_{i}>0\right)= \\
& \frac{\Gamma\left(\frac{1}{\alpha}+y_{i}\right)}{\Gamma\left(\frac{1}{\alpha}\right) \Gamma\left(y_{i}+1\right)} \frac{\left(\alpha \lambda_{i}\right)^{y_{i}}\left(1+\alpha \lambda_{i}\right)^{-\left(\frac{1}{\alpha}+y_{i}\right)}}{1-\left(1+\alpha \lambda_{i}\right)^{-\left(\frac{1}{\alpha}\right)}}
\end{aligned}
$$

where $\Gamma$ indicates the gamma distribution, $y_{\mathrm{i}}=1,2, \ldots \ldots, i=$ $1,2, \ldots, n$, and $\alpha>0$.

The $\alpha$ parameter shows up in the calculation of the conditional variance of $y_{\mathrm{i}}$ (Grogger and Carson 1988) and if greater than 0 , guarantees that the variance is greater than the mean. As $\alpha$ approaches 0 , however, the negative binomial model degenerates to the Poisson. Thus, testing for $\alpha=0$ provides a case for selecting the negative binomial over the Poisson, and indirectly the presence of overdispersion. The log-likelihood function for (2) is also described by Grogger and Carson (1988) and the parameters can be estimated with maximum likelihood methods.

The truncated count model programs in LIMDEP version 6.0 (Greene 1992) were used to estimate recreation demand parameters. The dependent variable was the number of trips to the forest from a postal code. The independent variables are described below.

\section{Specification of Variables}

Aggregate TCM analyses involve regressing trips from some aggregate population unit on a set of independent variables. Issues with aggregate analysis involve: 1) weighting to account for the population of the aggregate unit, 2) the choice of other suitable variables that reflect relevant socioeconomic differences between the aggregate units, and 3) the construction of the "price" of a trip (or travel costs). Hellerstein's (1991) aggregate TCM study provides a good guide to the weighting issue and the choice of variables.

The weighting issue is related to the assumption that the individuals within an aggregate unit are homogeneous in terms of travel costs and socioeconomic characteristics (Fletcher et al. 1990). This condition means that the trips from an aggregate unit containing $W$ individuals can be modelled as a Poisson process with a parameter equal to the sum of the individual $\lambda$ 's across all $W$ individuals in the unit. Hellerstein (1991) suggests that this $\operatorname{sum}\left(\lambda_{\mathrm{w}}=\Sigma_{\mathrm{i}}{ }^{\mathrm{w}} \lambda_{\mathrm{i}}\right)$ is also Poisson distributed with the result that the distribution of trips is $\operatorname{Prob}(Y=n)=\left(\exp ^{-}\right.$ $\left.\lambda_{\mathrm{w}}\right)\left(\lambda_{\mathrm{w}}\right)^{\mathrm{n} / n !}$. Thus, the population of each aggregate unit must be included in the model either by weighting each unit in the count estimation by its population, or by including the natural logarithm of its population as an independent variable in the regression which is mathematically equivalent. We used the latter method and a priori expected the sign of the parameter on this variable to be positive, reflecting the fact that larger postal code populations result in larger numbers of trips to the forest.

The socioeconomic variables used as independent regressors came from linking the postal code with 1991 Statistics Canada census data. A set of variables were derived for each postal code identified in the permits that was similar to those used by Hellerstein (1991). These included an annual household income measure, the percentage unemployed, the percentage with a post secondary education level, the percentage of people $<17$ years of age, and the percentage of people $>65$ years of age. Hellerstein (1991) also utilized a poverty measure, but we could not capture a similar variable from the Canadian census data. Prior expectations of the influence of these variables on trip frequency were unknown. Hellerstein's (1991) results could be used as a guide, but his study involved US data and the recreation destination was distinctive. However, the fact that the Rocky-Clearwater Forest attracts a large number of rural 
local visitors (McFarlane et al. 1996), and that many are either families with young children or retired people, suggests that the age variables should have positive signs. The influence of unemployment and education levels on visits remained unknown.

Travel costs were imputed using standard travel cost estimation methods. This involved both the entry fee and the estimated costs involved in travelling to the area and also to a substitute area, the Bow-Crow Forest. Substitute prices can be important in travel cost models (Rosenthal 1987). The following formula identifies the travel cost calculation:

travel cost $=\$ 0.22 \times$ distance $+[1 / 80 \times 1 / 3 \times($ income $/ 2040)$ $\times$ distance $]+[2 \times \$ 9.00]$

This formula identifies three components of travel cost: i) the out-of-pocket expenses for the vehicle, estimated at $\$ 0.22 \mathrm{~km}^{-1}$ (Alberta Motor Association, pers. comm.), ii) the opportunity cost of travel time, estimated at one-third of the wage rate (Cesario 1976), and the estimated cost of a typical stay at an FRA in the Rocky-Clearwater or Bow-Crow Forests. Recall that the distance measure was estimated using GIS, and that it involved the distance (in $\mathrm{km}$ ) from the centroid of each postal code to Fish Lake, which is centrally located in the RockyClearwater Forest. Note that in the second term an average speed of $80 \mathrm{kph}$ is assumed, and that the wage rate involves income

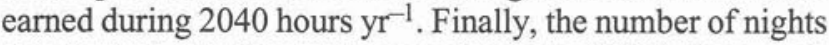
by a typical camping party was about two (McFarlane et al. 1996), and that the typical fee paid was $\$ 9.00$ night $^{-1}$.

The sign for the parameter on travel cost to the RockyClearwater Forest was expected to be negative, indicating that the farther away a postal code was from the forest, the fewer trips were taken. The sign for the parameter on the substitute recreation site (Ghost Lake) was expected to be positive, supporting the notion that the closer one is to the substitute the fewer trips were taken to the Rocky-Clearwater Forest. These expectations of the influence of these parameters on visits result from economic theory, which predicts that the amount of a commodity purchased is negatively influenced by rises in its own price, yet is positively influenced by rises in the price of its substitutes.

\section{Results and Discussion}

The maximum likelihood estimates of parameters from the truncated Poisson and negative binomial count models are provided in Table 1. The signs of the parameters from the two models are similar and their magnitudes are not markedly different. The $t$-statistics for the Poisson parameters are higher than those for the negative binomial. However, they are not distinctly larger as found in other studies comparing these two count models in recreation demand settings (Grogger and Carson 1988). This suggests that the Poisson model in this Alberta example may not be affected by overdispersion and that the negative binomial is not offering any distinctive advantages in estimation. Indeed the statistical insignificance of the $\alpha$ parameter (Table 1) confirms this suggestion. Thus, the Poisson model is put forward as the best representation of recreation trip demand in this empirical study of the Rocky-Clearwater Forest.

The signs and significance of most of the Poisson parameters met prior expectations. The parameter on estimated travel costs to the Rocky-Clearwater Forest is negative and statistically sig-
Table 1. Parameters from truncated count models explaining the number of trips to Forest Recreation Areas in the Rocky-Clearwater Forest, Alberta in 1994

\begin{tabular}{|c|c|c|c|}
\hline \multirow[b]{2}{*}{ Variables $^{1}$} & \multicolumn{2}{|c|}{$\begin{array}{c}\text { Coefficients } \\
\text { (t-ratio) }\end{array}$} & \multirow[b]{2}{*}{$\begin{array}{c}\text { Mean value of } \\
\text { variable }\end{array}$} \\
\hline & Poisson & $\begin{array}{l}\text { Negative } \\
\text { binomial }\end{array}$ & \\
\hline Intercept & $\begin{array}{l}-6.9164 \\
(-47.32)\end{array}$ & $\begin{array}{l}-13.031 \\
(-0.06)\end{array}$ & \\
\hline RCFTC & $\begin{array}{l}-0.0190 \\
(-61.39)\end{array}$ & $\begin{array}{l}-0.0158 \\
(-26.15)\end{array}$ & 215.80 \\
\hline ВСТC & $\begin{array}{l}0.0039 \\
(17.23)\end{array}$ & $\begin{array}{l}0.0057 \\
(12.18)\end{array}$ & 205.60 \\
\hline Income & $\begin{array}{l}-0.0016 \\
(-9.28)\end{array}$ & $\begin{array}{l}-0.0017 \\
(-6.93)\end{array}$ & 49.48 \\
\hline \%Unemploy & $\begin{array}{l}-0.0210 \\
(-7.22)\end{array}$ & $\begin{array}{l}-0.0384 \\
(-7.98)\end{array}$ & 7.86 \\
\hline \%University & $\begin{array}{l}0.0046 \\
(1.71)\end{array}$ & $\begin{array}{l}-0.0104 \\
(-2.45)\end{array}$ & 13.68 \\
\hline$\%<17$ & $\begin{array}{l}0.0097 \\
(3.32)\end{array}$ & $\begin{array}{l}0.0009 \\
(-0.28)\end{array}$ & 26.43 \\
\hline$\%>65$ & $\begin{array}{l}0.0205 \\
(7.84)\end{array}$ & $\begin{array}{l}0.0006 \\
(-0.12)\end{array}$ & 9.23 \\
\hline $\ln \mathrm{POP}$ & $\begin{array}{r}1.5337 \\
(131.747)\end{array}$ & $\begin{array}{c}1.2167 \\
(24.35)\end{array}$ & 6.91 \\
\hline tor & & $\begin{array}{l}6547.8 \\
(0.005)\end{array}$ & \\
\hline Log likelihood & -9095.75 & -5530.17 & \\
\hline
\end{tabular}

${ }^{1}$ Dependent variable is the number of visits by individuals in a postal code to the Rocky-Clearwater Forest. Independent variables are: RCFTC is travel cost to the Rocky-Clearwater Forest; BCTC is the travel cost to the BowCrow Forest, a substitute recreation area south of the Rocky-Clearwater; Income is average household income (in \$1000s) per postal code; \%Unemploy is the $\%$ of the residents in the postal code unemployed; \%University is the $\%$ of the residents in postal code with a university degree; $\%<17$ is the $\%$ of the postal code population less than 17 years of age; $\%>65$ is the $\%$ of the postal code population greater than 65 years of age; InPOP is the natural logarithm of the postal code population.

nificant. The substitute price, the travel cost to the BowCrow Forest, is positive as predicted by economic theory and also statistically significant. The income parameter is negative and significant. While this negative sign is contrary to economic theory, it is commonly found in travel cost models and may reflect the fact that the recreation activity and/or destination being examined here may not be preferred by high income groups, or that higher income groups have less time to recreate.

The parameters on the young and old age categories are positive, while the parameter of unemployment is negative. This suggests that areas with low levels of unemployment and more residents $<17$ and $>65$ years of age take more trips to the RockyClearwater Forest. The influence of the age variables meets our prior expectations. Education levels apparently did not influence visitation frequency as the parameter was not statistically significant.

These results were compared with those of Hellerstein (1991) for the Boundary Waters Canoe Area, who found 
that the negative binomial model performed the best in estimating trip demand. His travel cost variables performed similar to those for our model. However, he found opposite results for some of the other comparable explanatory variables: income levels were positive and the young and old age categories were negative. The contrary findings are probably due to the different markets that each of the two recreation areas attract. The Boundary Waters is a very popular backcountry or wilderness park in the US and has a legendary reputation as evidenced by a large literature describing its virtues and history (Backes 1991). Thus, one may expect it to attract high income earning individuals, and the backcountry nature would likely not attract visitors $<17$ and $>65$ years of age. In contrast, FRAs in the Rocky-Clearwater Forest provide vehicle-based camping experiences and attract mostly rural Albertans living in the surrounding communities (McFarlane et al. 1996).

The Poisson model of trip demand to the Rocky-Clearwater Forest allows the estimation of consumer surplus per predicted trip. An issue in this estimation is that we have estimated demand conditional on taking a positive quantity of trips, while the unconditional demand curve is of primary interest (Creel and Loomis 1990). It is thus convention to use the truncated model to approximate the untruncated one (Creel and Loomis 1990; Gomez and Ozuna 1993; Yen and Adamowicz 1993). This results in a logarithmic function where consumer surplus per trip is equal to the negative inverse of the travel cost parameter $\left(-1 / \beta_{\mathrm{TC}}\right.$ ) (Adamowicz et al. 1989). For the trips we examine to the Rocky-Clearwater Forest during 1994 this results in an estimated value of about $\$ 52.77$ trip $^{-1}$. Aggregating this for the 13,997 trips yields a total annual benefit of camping at the FRAs in the forest of almost $\$ 750,000$.

Some comments on the estimated values seem warranted. First, the per trip value appears somewhat higher than other per trip estimates for camping in forested areas in the US (Richards and Brown 1992; Sorg and Loomis 1984). The consumer surplus estimate is only about $26 \%$ of the estimated average cost of a trip to the forest (Table 1). However, there are virtually no other Canadian studies of similar recreational activities that can be compared, and our estimates are not that much higher than the US studies once exchange rates and inflation are taken into account. The aggregate benefit estimates on the other hand, do not seem far from similar studies in the US. For example, Hellerstein (1991) reports aggregate annual surplus estimates of about $\$ 1.32$ to $\$ 1.69$ million US for the Boundary Waters Canoe Area, and Richards and Brown (1992) report annual estimates of $\$ 48,000$ to $\$ 111,000$ US for single campgrounds in Arizona.

Second, our value estimates are derived from a truncated count model. Yen and Adamowicz (1993) found consumer surplus estimates from truncated count models to be higher than those from untruncated models using recreational hunting site choice data. This finding, if indeed general, suggests that further work in nontimber valuation using the approach proposed here should address the issue of gathering data from nonvisitors to the recreation area. This would require information on the independent variables associated with postal codes from which we did not observe visits. The expanded data set would then not be truncated and untruncated count estimators could be used to derive demand models as in Hellerstein's (1991) study. The analysis required for this was beyond the scope of this study. However, given advances in GIS technology this may be a fruitful avenue for research in the future. The appeal of this expansion may be the fact that once the travel cost models and GIS programming are established, then estimates of recreation benefits can occur at any time in the future.

\section{Conclusions}

Our primary goal in this research was to demonstrate that existing data collection systems in forest recreation management could be linked with GIS and economic methods to provide nontimber values. A secondary goal was to utilize existing econometric methods to actually derive nontimber value information for forests in Alberta. The permit system used by the Alberta Land and Forest Service, once adjusted, proved to be adequate to derive simple travel cost models that could then be used to estimate nontimber values. The adjustments included: 1) an expansion of information collected on people using recreation areas; 2) using GIS technology to link permits with the provincial road network to calculate travel distances; 3 ) linking postal codes with national census data for estimates of socioeconomic data; and 4) application of statistical methods to estimate recreation demand models. While further refinements of these elements can improve aspects of the valuation effort, this study supports the notion of developing and adjusting permit systems to capture information beyond that needed for accounting purposes. If this development were to occur on a sustained temporal and wider spatial basis, then nontimber values could be estimated cost effectively for a variety of activities, land bases and time periods. Such a development would be invaluable if nontimber values are included more extensively in future forest management decisions.

\section{Acknowledgements}

We gratefully acknowledge the technical assistance of Maureen Dolphin, Ramona Maraj, Bonnie Rush, Robert Lindsay, and Anne Cardasilaris. We also thank Kerry Edwards at the Alberta Parks Services and Dave Coish at Alberta Land and Forest Service for their assistance with several aspects of the study. We are pleased to acknowledge the Canada-Alberta Partnership Agreement in Forestry which funded the study; thanks to Steve Price and Marjorie Stephen for their assistance in this regard. Finally we thank Vic Adamowicz and Jeff Englin for comments on this paper.

\section{References}

Adamowicz, W.L., J.J. Fletcher and T. Graham-Tomasi. 1989. Function form and the statistical properties of welfare measures. Amer. J. Agric. Econ. 71:414-421.

Backes, D. 1991. Canoe country: An embattled wilderness. Northwood Press, Minocqua, WI.

Cameron, A.C. and P.K. Trivedi. 1986. Econometric models based on count data: comparisons and application of some estimators and tests. J. Appl. Econometrics 1: 29-53.

Cesario, F.J. 1976. Value of time in recreation benefit studies. Land Econ. 52: 32-41.

Creel, M.D. and J.B. Loomis. 1990. Theoretical and empirical advantages of truncated count data estimators for analysis of deer hunting in California. Am. J. Agric. Econ. 72: 434 441.

ESRI Inc. 1992. The digital chart of the world for use with Arc/Info. Environ. Syst. Res. Inst. Inc., Redlands, CA.

Fletcher, J.J., W.L. Adamowicz and T. Graham-Tomasi. 1990. The travel cost model of recreation demand: theoretical and empirical issues. Leis. Sci. 12: 119-147.

Gomez, I.A. and T. Ozuna. 1993. Testing for overdispersion in trun- 
cated count data recreation demand functions. J. Environ. Manage. 37: $117-125$.

Gourieroux, C., A. Monfort, and A. Trogon. 1984. Pseudo maximum likelihood methods: Applications. Econometrica 52: 701-720. Grogger, J.T. and R.T. Carson. 1988. Models for truncated counts. J. Appl. Econometrics 6: 225-238.

Greene, W. 1992. LIMDEP Version 6.0. Econometric Software, New York, NY.

Hausman, J., B. Hall, and Z. Griliches. 1984. Econometric models for count data with an application to the patents - R\&D relationship. Econometrica 52: 909-938.

Hellerstein, D.M. 1991. Using count data models in travel cost analysis with aggregate data. Am. J. Agric. Econ. 73: 860-866.

McFarlane, B.L., P.C. Boxall. and M. Gartrell. 1996. Forest recreation area campers in the Rocky-Clearwater Forest of Alberta. Info. Rep. (forthcoming), North. For. Cent., Can. For. Serv., Edmonton, Alberta.

McKenney, D.M. and R. Sarker. 1994. An overview of nonwood valuation efforts in Ontario. For. Chron. 70: 47-54.
Offenbach, L.A. and B.K. Goodwin. 1994. A travel-cost analysis of the demand for hunting trips in Kansas. Rev. Agric. Econ. 16: 55-61. Richards, M.T. and T.C. Brown. 1992. Economic value of campground visits in Arizona. USDA For. Serv., Res. Paper RM-305, Fort Collins, CO.

Rosenthal, D.H. 1987. The necessity for substitute prices in recreation demand analysis. Am. J. Agric. Econ. 69: 828-837.

Smith, V.K. and R.J. Kopp. 1980. The spatial limits of the travel cost recreational demand model. Land Econ. 56: 1-8.

Sorg, C. and J.B. Loomis. 1984. Empirical estimates of amenity forest values: A comparative review. USDA Forest Service, Gen. Tech. Rep. RM-107, Fort Collins, CO.

Statistics Canada. 1992. 1991 postal code conversion file users' guide. Geography Div., Stats. Can., Ottawa, ON.

Yen, S.T. and W.L. Adamowicz. 1993. Statistical properties of welfare measures from count-data models of recreation demand. Rev. Agric. Econ. 15: 203-215. 